\title{
Changing hepatitis A epidemiology in the European Union: new challenges and opportunities
}

C M Gossner (Celine.Gossner@ecdc.europa.eu) ${ }^{1,2,3}$, E Severi¹,3, N Danielsson ${ }^{1}$, Y Hutin ${ }^{4}$, D Coulombier ${ }^{1}$

1. European Centre for Disease Prevention and Control (ECDC), Surveillance and Response Support Unit, Stockholm, Sweden

2. School of Public Health and Primary Care (CAPHRI), Maastricht University Medical Center (MUMC+), Maastricht, the Netherlands

3. These authors contributed equally to the paper

4. European Centre for Disease Prevention and Control (ECDC), Public Health Capacity and Communication, Stockholm, Sweden

Citation style for this article:

Gossner CM, Severi E, Danielsson N, Hutin Y, Coulombier D. Changing hepatitis A epidemiology in the European Union: new challenges and opportunities. Euro Surveill. 2015;20(16):pii=21101. Available online: http://www.eurosurveillance.org/ViewArticle.aspx?Articleld=21101

Article submitted on 24 February 2014 / published on 23 April 2015

This perspective on hepatitis A in the European Union and European Economic Area (EU/EEA) presents epidemiological data on new cases and outbreaks and vaccination policies. Hepatitis A endemicity in the EU/EEA ranges from very low to intermediate with a decline in notification rates in recent decades. Vaccination uptake has been insufficient to compensate for the increasing number of susceptible individuals. Large outbreaks occur. Travel increases the probability of introducing the virus into susceptible populations and secondary transmission. Travel medicine services and healthcare providers should be more effective in educating travellers and travel agents regarding the risk of travel-associated hepatitis A. The European Centre for Disease Prevention and Control (ECDC) endorses the World Health Organization's recommendations on vaccination of high-risk groups in countries with low and very low endemicity and on universal vaccination in countries with intermediate endemicity. Those recommendations do not cover the use of hepatitis $A$ vaccine to control outbreaks. ECDC together with EU/ EEA countries should produce evidence-based recommendations on hepatitis A immunisation to control outbreaks. Data about risk behaviours, exposure and mortality are scarce at the EU/EEA level. EU/EEA countries should report to ECDC comprehensive epidemiological and microbiological data to identify opportunities for prevention.

\section{Hepatitis A}

This paper is a perspective on hepatitis $A$ in the European Union and European Economic Area (EU/EEA) taking account of epidemiological data on new cases and outbreaks, and on vaccination policies.

Hepatitis $A$ is a common acute viral infection caused by hepatitis A virus (HAV) that affects 120 million people annually worldwide [1]. The virus spreads mostly through the faecal-oral route via person-to-person contact or ingestion of contaminated food or water; in rare cases, transmission can also occur via infected blood.
HAV belongs to the family Picornaviridae; six genotypes have been identified, with subtypes $A$ and $B$ of genotypes I, II, and III infecting humans [2].

Young children often have asymptomatic HAV infection. The proportion of symptomatic infection and severe disease increases with age. The incubation period is 30 days ranging from 15 to 50 days. Symptoms include fever, diarrhoea, fatigue, anorexia, nausea, dark-coloured urine and jaundice. Hepatitis A illness ranges from mild to severe and lasts from two weeks to several months. Bi- or multiphasic relapsing hepatitis with a duration of up to 40 weeks may complicate the course in 6 to $10 \%$ of symptomatic HAV infections [3] but recovery is complete and no chronic infections have been reported. Immunity after infection is lifelong. HAV infection rarely causes fulminant hepatitis and liver failure (overall case fatality ratio: 0.1 to $0.3 \%$ ). Patients with underlying chronic liver disease and people older than 50 years have higher case fatality ratios (1.8\%) [4].

HAV survives in the environment and resists many common food preservation methods including drying or freezing [5]. Hence, food can be a vehicle of HAV transmission. Contamination with HAV early in the production chain of commercial food products can result in large, prolonged and geographically dispersed outbreaks $[6,7]$.

\section{Geographical distribution}

The annual risk of infection with HAV is associated with indicators of socioeconomic development, hygiene and access to safe water. Because few countries report notification rates, the World Health Organization (WHO) estimates the level of endemicity based on the age-specific seroprevalence estimates of HAV antibodies in the population. Seroprevalence varies widely among countries [1]. In areas with high endemicity (e.g. Sub-Saharan Africa and parts of South-East Asia) at least $90 \%$ of people have antibodies against HAV by 

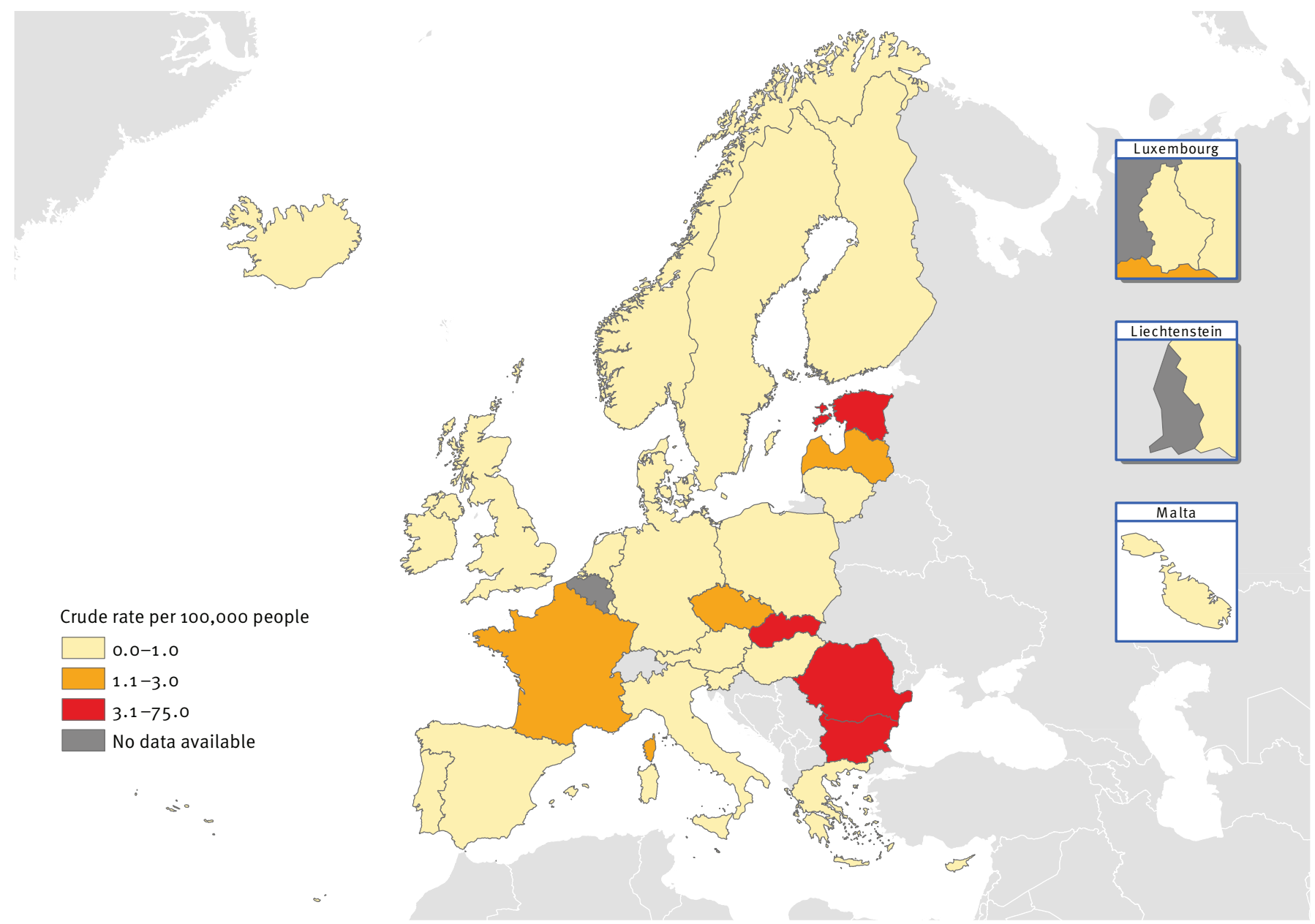

EEA: European Economic Area; EU: European Union.

age 10 years. Outbreaks are rarely reported from these areas because most children have asymptomatic infections and the majority of adults are immune. Areas of intermediate endemicity are defined asthose with at least $50 \%$ seroprevalence by age 15 years, withless than $90 \%$ by age 10 years, and include southern and eastern parts of the European Union (EU), China, Latin America, northern Africa, the Middle East and Russia. In these areas, a larger proportion of the population reaches adulthood uninfected, leading to higher susceptibility in older age groups and recurrent outbreaks of symptomatic disease. Finally, in areas with low endemicity (seroprevalence of at least $50 \%$ by age 30 years and less than $50 \%$ by age 15) and very low endemicity (less than $50 \%$ seroprevalence by age 30 years) such as western and northern parts of the EU and European Economic Area (EEA), Australia, Canada, Japan, and the United States (US), virus circulation is limited and the proportion of susceptible individuals is large in all age groups.

\section{Epidemiology of hepatitis A in the EU/EEA} The notification rate in the EU/EEA has fallen between 1997 and 2011, from 10.0 to 2.5 per 100,000 population $[8,9]$. In 2011 , of the 28 EU/EEA countries reporting to The European Surveillance System (TESSy), 21 reported notification rates of up to one per 100,000 population while four central and eastern EU Member States reported notification rates above three per 100,000 population (Figure 1). Male cases accounted for $56 \%$. Children aged five to 14 years were most affected and there was a peak in reported cases in September and October as people returned from holidays and family visits in endemic countries [9-11]. Most countries that report cases to TESSy do not include information about risk behaviour and exposure, preventing analysis on risk factors. From 2005 to 2012, the reported proportion of cases infected abroad ranged from 49 to $80 \%$ in Sweden (average: 65\%) [12] and was estimated at $37 \%$ in Germany and $36 \%$ in France in the same time period $[13,14]$. In France, $50 \%$ of hepatitis $A$ cases resulted from secondary transmission from a primary case: $80 \%$ of these occurred through a household contact [14]. Case reports to TESSy do not consistently include 
EU/EEA countries recommending hepatitis A virus vaccination to groups defined by the WHO as at high risk for exposure or at risk of serious clinical outcome, $2013\left(\mathrm{n}=30^{\mathrm{a}}\right)$

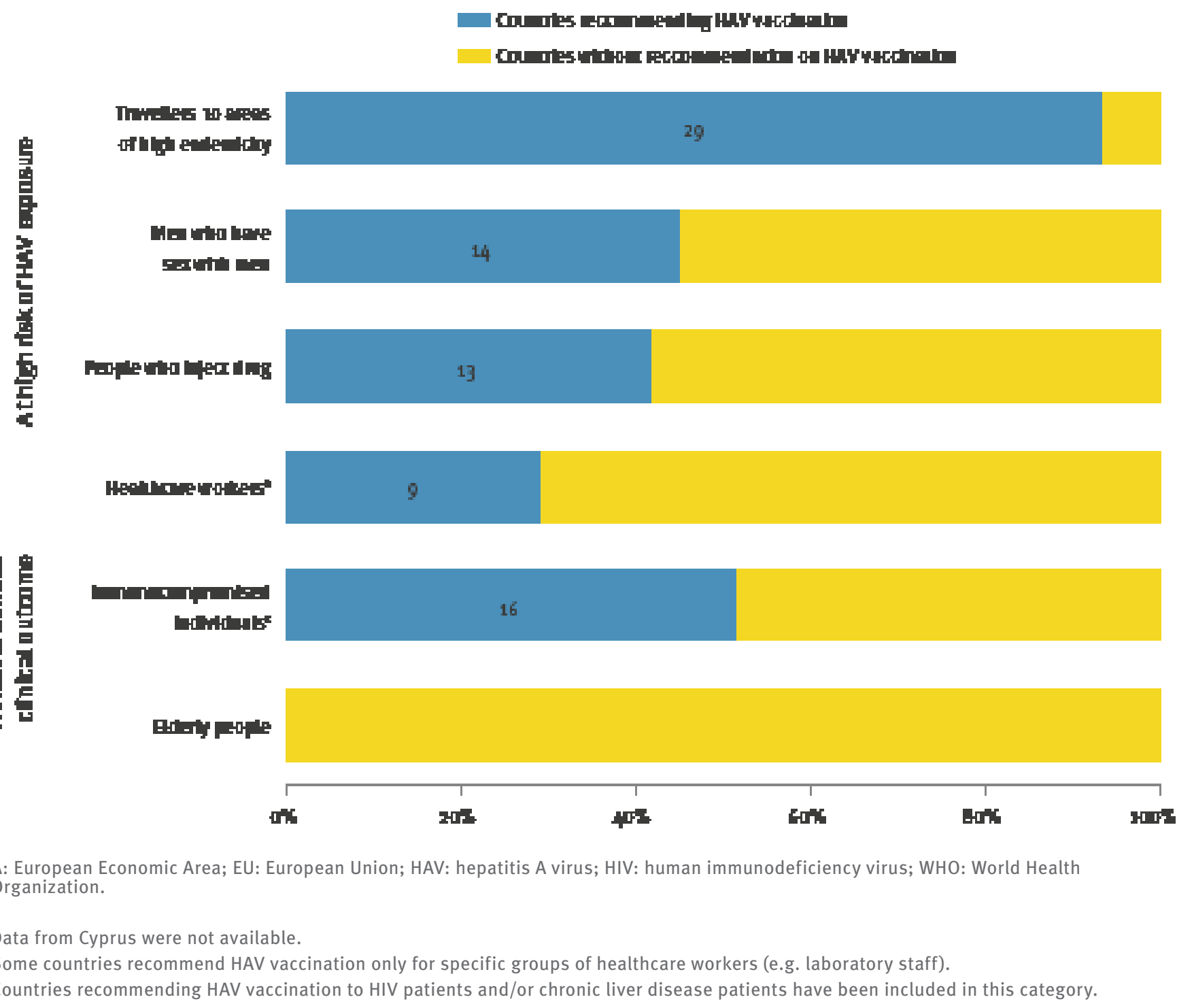

Source: Epidemic Intelligence Information System for Vaccine Preventable Diseases, websites of National Public Health Institutes and Ministries of Health in the European Union and European Economic Area.

outcome information which makes it impossible to monitor case fatality ratios or the proportion of cases with complications.

\section{Risk groups and vaccination in EU/EEA}

Susceptible individuals from the EU/EEA countries at higher risk of exposure to HAV include travellers to areas of high endemicity, people visiting friends and family in high endemicity areas, expatriates living in these areas, marginalised groups living under poor sanitary conditions, people who inject drugs, men who have sex with men [1] and, very rarely, recipients of blood and blood products [15]. The number of travellers from the EU/EEA to destinations with high hepatitis A endemicity is increasing. As a result, those destinations may appear less exotic and individuals may be less prone to consult travel medicine clinics before departure.

Inactivated hepatitis A vaccines are safe and effective for both pre- and post-exposure prophylaxis [16]. The WHO recommends routine childhood vaccination in countries with intermediate endemicity, including southern and eastern EU countries, but not in high endemicity countries. In western and northern EU/EEA countries, where endemicity ranges from low to very low, the WHO recommendation is to vaccinate only high-risk groups [1]. Some EU countries with intermediate endemicity recommend universal vaccination at the national level (e.g. Greece since 2008 [17]) or at the regional level (e.g. Catalonia, Spain [18] or Apulia, Italy [19] since 1998). Most EU/EEA countries have issued recommendations at least for some risk groups (Figure 
2) but those are not necessarily associated with programmes, budgeted resources and coverage monitoring $[20,21]$. An economic evaluation conducted in the US estimated that the universal hepatitis $A$ vaccination for children implemented in 2006 in the US led to herd immunity and has been a cost saving intervention for the first three years after introduction and costneutral over the first 10 years of the programme [22]. Information campaigns and increased access through removal of financial barriers can increase uptake in the EU/EEA countries. For example, Denmark and Norway provide hepatitis $A$ vaccine free of charge to people with chronic liver diseases and people who inject drugs [17]. The WHO does not provide recommendations on the use of hepatitis A vaccination for outbreak control: although immunisation has been reported to be effective in controlling outbreaks in small communities, there is still lack of evidence on the wide-spread use of vaccination to control large outbreaks [1].

\section{Outbreaks in the EU/EEA in the past decade}

Several hepatitis A outbreaks have been reported in the EU/EEA in the past decade. Some have affected high risk groups while others have spread in the general population. We divided the outbreaks in three groups, depending on the mode and setting of infection.

Travel-related outbreaks were defined as those affecting EU/EEA residents while abroad, regardless of the mode of transmission. From November 2012 to June 2013, over 100 travellers to Egypt from 14 EU/EFTA countries were infected with HAV of sub-genotype IB $[23,24]$. Similar outbreaks among European travellers to Egypt were reported in 2004 [25] and 2008 [21]. For all these outbreaks, a food- and/or waterborne transmission was plausible.

Community-wide outbreaks were defined as those for which the primary mode of transmission was personto-person contact, including among people who use drugs. These outbreaks often start within high-risk groups and later spread to the general community (e.g. in Latvia in 2008 [26]). Also religious groups, migrants and ethnic minorities have been affected (e.g. the Orthodox Jewish community in London 2011 [27]).

Food-borne outbreaks were defined as those for which consumption of contaminated food in the EU/EEA was the primary vehicle of infection. From 2009 to 2011, three clusters of HAV infection with sub-genotype IB in France, the Netherlands and the United Kingdom were associated with consumption of semi-dried tomatoes from Turkey $[6,7,28]$. In the first half of 2013, two different outbreaks of hepatitis A associated with consumption of frozen berries were reported, one in Denmark, Finland, Norway and Sweden (sub-genotype IB) [29] and the other in Italy and Ireland (sub-genotype IA) [30]. In several outbreaks associated with fresh food products, investigations pointed to food handlers involved in harvesting or preparation of the products as the source of contamination, for example in 2004 in Belgium [31].

\section{Why do we see outbreaks in the EU and what to expect in the future?}

The susceptible proportion of the EU/EEA population is growing fast as a result of declining HAV incidence. HAV vaccine uptake has not been high enough to compensate for the fall in natural immunity. On the one hand, as disease severity increases with the patient's age, increasing numbers of susceptible adults could potentially result in more severe disease, and eventually in higher case fatality ratios. On the other hand, the lower rates could also compensate for the higher case fatality ratios and the overall mortality might not increase or decrease.

'Seeding events', when HAV is introduced to a population with low immunity via a food- or travel-associated primary case, may lead to community transmission. However, person-to-person transmission is uncommon. In the outbreak in Denmark, Finland, Norway and Sweden in 2013, associated with consumption of frozen berries, only $10 \%$ of cases were secondary cases [29].

Self-controls by the industries and official controls by the food safety authorities Regulatory controls and industry auto-controls are unlikely to completely prevent the importation of HAV-contaminated foods from highly endemic countries into the EU/EEA.* The infective dose is presumably low [32] and it is technically challenging to detect HAV contamination in food products [33]. Because the virus is resistant to many preservation methods, contaminated preserved products (e.g. frozen fruits and dried vegetables) may remain on the market over long periods of time and result in slowly propagating multinational outbreaks in which the cases are widely dispersed in time and space.

Investigations of food-borne hepatitis A outbreaks are challenging. Cases may have difficulties remembering what they ate four weeks before onset of symptoms, and the opportunities to sample implicated food for testing are often limited. If the suspected vehicle is a mixed food item (e.g. mixed berries), it may be impossible to identify the contaminated ingredient.

Unvaccinated EU/EEA travellers visiting endemic countries are at risk of infection. If infected abroad, they expose their close contacts to secondary transmission after returning home. Healthcare providers and travellers underestimate the risk of hepatitis A in tourist destinations. Twenty per cent of returning travellers with hepatitis A had not been vaccinated against hepatitis $A$ despite receiving pre-travel medical advice [34].

Better surveillance and increased international collaboration within the EU/EEA region may partially explain the increased number of multinational outbreaks 
reported since 2012. Increasing availability and affordability of molecular characterisation techniques has made it possible to link apparently sporadic cases and to associate them with slowly evolving multinational outbreaks. Through the pooling of epidemiological and microbiological information at the EU/EEA level, the Epidemic Intelligence Information System (EPIS) for Food and Waterborne Disease and for Vaccine Preventable Diseases of the European Centre for Disease Prevention and Control (ECDC) facilitate communication among disease experts in the EU/EEA countries and allow rapid identification of the multicountry dimension of reported outbreaks [35]. In linking geographically and temporarily dispersed cases, RNA sequencing techniques for HAV isolates have facilitated investigations of multicountry outbreaks. Improved surveillance in the EU/EEA may lead to the identification of more outbreaks at an earlier stage in the future.

\section{Conclusions and recommendations}

Hepatitis A notification rates have declined in the past two decades in the EU/EEA and this has resulted in a growing proportion of adults who are susceptible to HAV infection. Higher mean age at the time of infection could result in more symptomatic infection and more severe disease. Unfortunately, HAV data reports to TESSy do not include information that would allow assessing the impact of this epidemiological shift on disease severity and case fatality ratio [1]. There are gaps in the vaccination uptake among high-risk groups in low and very low endemicity countries $[20,24]$, and among populations living in intermediate endemicity areas. In addition, international recommendations on vaccination strategies for outbreak control are lacking. Travel continues to cause imported cases and secondary transmission. Outbreaks provide valuable information on missed opportunities for prevention.

On the basis of these conclusions, we recommend improving our knowledge on the epidemiology of hepatitis $A$ as well as prevention efforts: Firstly, ECDC should work closely with the EU Member States to ensure better reporting of cases through TESSy, including information on mode of transmission, risk behaviours and deaths. Secondly, EU/EEA countries should follow WHO recommendations and consider (i) including hepatitis $A$ vaccination in routine childhood vaccination schedules in regions with intermediate endemicity and (ii) vaccinating individuals at high risk of infection in countries with low and very low endemicity. Thirdly, ECDC together with the EU/EEA countries should also consider examining the evidence of the effectiveness of hepatitis $A$ vaccine use in controlling outbreaks in the EU/EEA.* Fourthly, travel medicine services and healthcare providers must educate travellers and travel agents regarding the risks of travel-associated hepatitis $A$, emphasising that staying in all-inclusive luxury resorts does not protect travellers from infection because food and water might be contaminated [21-25]. Finally, Member States and ECDC should gather information from outbreaks to identify missed opportunities for prevention. Useful actions are (i) timely reporting of signals of multinational outbreaks though EPIS, (ii) prompt sharing of epidemiological and microbiological data on human and food safety, and (iii) sharing of testing protocols and interpretation frameworks for sequencing results.

\section{Acknowledgments}

We are very grateful to all colleagues in the EU/EEA countries providing data to TESSy, EPIS-FWD and EPIS-VPD. We warmly thank Denisa Janta, Adriana Pistol, Maria Koliou, Koen De Schrijver and Dragoslav Domanovic for their support in providing relevant information for this article.

\section{Conflict of interest}

None declared.

\section{Authors' contributions}

Céline Gossner and Ettore Severi have collected and analysed the data, and drafted the manuscript. Niklas Danielson, Yvan Hutin and Denis Coulombier have substantially contributed to the drafting and revision of the manuscript.

\section{${ }^{\star}$ Erratum}

The sentence "Self-controls by the industries and official controls by the food safety authorities Regulatory controls and industry auto-controls are unlikely to completely prevent the importation of HAV-contaminated foods from highly endemic countries into the EU/EEA." was corrected to read "Self-controls by the industries and official controls by the food safety authorities are unlikely to completely prevent the importation of HAV-contaminated foods from highly endemic countries into the EU/EEA." on 7 July 2015.

\section{References}

1. WHO position paper on hepatitis A vaccines - June 2012. Wkly Epidemiol Rec. 2012;87(28/29):261-76. PMID:22905367

2. Desbois D, Couturier E, Mackiewicz V, Graube A, Letort MJ, Dussaix E, et al. Epidemiology and genetic characterization of hepatitis A virus genotype IIA. J Clin Microbiol. 2010;48(9):3306-15. http://dx.doi.org/10.1128/JCM.00667-10 PMID:20592136

3. Schiff ER. Atypical clinical manifestations of hepatitis A. Vaccine. 1992;10(Suppl 1):S18-20. http://dx.doi. org/10.1016/0264-410X(92)90534-Q PMID:1475999

4. Heymann DL, editor. Control of communicable diseases manual. 19th ed. Washington: American Public Health Association; 2008.

5. Baert L, Debevere J, Uyttendaele M. The efficacy of preservation methods to inactivate foodborne viruses. Int J Food Microbiol. 2009;131(2-3):83-94. http://dx.doi. org/10.1016/j.ijfoodmicro.2009.03.007 PMID:19349089

6. Fournet N, Baas D, van Pelt W, Swaan C, Ober H, Isken L, et al. Another possible food-borne outbreak of hepatitis $A$ in the Netherlands indicated by two closely related molecular sequences, July to October 2011. Euro Surveill. 2012;17(6):20079. PMID:22340976

7. Petrignani $M$, Harms $M$, Verhoef $L$, van Hunen $R$, Swaan $C$, van Steenbergen J, et al. Update: a food-borne outbreak of hepatitis A in the Netherlands related to semi-dried tomatoes in oil, January-February 2010. Euro Surveill. 2010;15(20):19572. PMID:20504389

8. European Centre for Disease Prevention and Control (ECDC). Annual epidemiological report on communicable diseases in Europe. Report on the status of communicable diseases 
in the EU and EEA/EFTA countries. Stockholm: ECDC; 2007. Available from: http://ecdc.europa.eu/en/publications/ Publications/0706_SUR_Annual_Epidemiological_ Report_2007.pdf

9. European Centre for Disease Prevention and Control (ECDC). Annual epidemiological report 2013. Reporting on 2011 surveillance data and 2012 epidemic intelligence data. Stockholm: ECDC; 2013. Available from: http://www. ecdc.europa.eu/en/publications/Publications/AnnualEpidemiological-Report-2013.pdf

10. Sane J, de Sousa R, van Pelt W, Petrignani M, Verhoef L, Koopmans M. Risk of hepatitis A decreased among Dutch travelers to endemic regions in 2003 to 2011. J Travel Med. 2014. [Epub ahead of print].

11. Tjon G, Xiridou M, Coutinho R, Bruisten S. Different transmission patterns of hepatitis $A$ virus for two main risk groups as evidenced by molecular cluster analysis. J Med Virol. 2007;79(5):488-94. http://dx.doi.org/10.1002/jmv.20821 PMID:17385681

12. Public Health Agency of Sweden. Hepatit A. [Hepatitis A]. Solna: Folkhälsomyndigheten. [Accessed: 25 Mar 2013]. Swedish. Available from: http://www.folkhalsomyndigheten. se/amnesomraden/statistik-och-undersokningar/ sjukdomsstatistik/hepatit-a/

13. Robert Koch Institute (RKI). Infektionsepidemiologisches Jahrbuch für 2007 [Annual epidemiological report on notifiable infectious diseases for 2007]. Berlin: RKI; 2008. German. Available from: http://www.rki.de/DE/Content/Infekt/ Jahrbuch/Jahrbuch_2007.pdf? blob=publicationFile

14. Institut de Veille Sanitaire (InVS). Hépatite A. Données épidemiologiques 2006-2012. [Hepatitis A. Epidemiological data 2006-2012]. [Accessed: 13 Dec 2013]. French. Available from: http://www.invs.sante.fr/Dossiers-thematiques/ Maladies-infectieuses/Maladies-a-declaration-obligatoire/ Hepatite-A/Donnees-epidemiologiques

15. Perevoscikovs J, Lenglet A, Lucenko I, Steinerte A, Payne Hallström L, Coulombier D. Assessing the risk of a community outbreak of hepatitis A on blood safety in Latvia, 2008. Euro Surveill. 2010;15(33):19640. PMID:20739001

16. Werzberger A, Mensch B, Kuter B, Brown L, Lewis J, Sitrin R, et al. A controlled trial of a formalin-inactivated hepatitis $A$ vaccine in healthy children. N Engl J Med. 1992;327(7):4537. http://dx.doi.org/10.1056/NEJM199208133270702 PMID:1320740

17. European Centre for Disease Prevention and Control (ECDC). Epidemic Intelligence Information System for Vaccine Preventable Diseases. Stockholm: ECDC. [Accessed: 13 Dec 2013].

18. Martínez A, Broner S, Torner N, Godoy P, Batalla J, Alvarez J, et al. Hepatitis $A$ outbreaks in the vaccination era in Catalonia, Spain. Hum Vaccin. 2011;7(sup1) Suppl;205-10.

19. Chironna M, Prato R, Sallustio A, Martinelli D, Tafuri S, Quarto $M$, et al. Hepatitis A in Puglia (South Italy) after 10 years of universal vaccination: need for strict monitoring and catchup vaccination. BMC Infect Dis. 2012;12(1):271. http://dx.doi. org/10.1186/1471-2334-12-271 PMID:23098290

20. Faber MS, Stark K, Behnke SC, Schreier E, Frank C. Epidemiology of hepatitis A virus infections, Germany, 20072008. Emerg Infect Dis. 2009;15(11):1760-8. http://dx.doi. org/10.3201/eid1511.090214 PMID:19891863

21. Couturier E, Roque-Afonso AM, Letort MJ, Dussaix E, Vaillant V, de Valk H. Cluster of cases of hepatitis A with a travel history to Egypt, September-November 2008, France. Euro Surveill. 2009;14(3):14. PMID:19161726

22. Armstrong GL, Billah K, Rein DB, Hicks KA, Wirth KE, Bell BP. The economics of routine childhood hepatitis $A$ immunization in the United States: the impact of herd immunity. Pediatrics. 2007;119(1):e22-9. http://dx.doi.org/10.1542/peds.2006-1572 PMID:17200247

23. European Centre for Disease Prevention and Control (ECDC). Outbreak of hepatitis $A$ virus infection in travellers returning from Egypt. Rapid risk assessment. Stockholm: ECDC; April 2013. Available from: http://www.ecdc.europa.eu/en/ publications/Publications/RRA-Outbreak-hepatitis-A-virusinfection-travellers-returning-from-Egypt.pdf

24. Sane I, MacDonald E, Vold L, Gossner C, Severi E, Outbreak Investigation Team. Multistate foodborne hepatitis A outbreak among European tourists returning from Egypt--need for reinforced vaccination recommendations, November 2012 to April 2013. Euro Surveill. 2015;20(4):21018. http://dx.doi. org/10.2807/1560-7917.ES2015.20.4.21018 PMID:25655054

25. Frank C, Walter J, Muehlen M, Jansen A, van Treeck U, Hauri AM, et al. Major outbreak of hepatitis A associated with orange juice among tourists, Egypt, 2004. Emerg Infect Dis. 2007;13(1):156-8. http://dx.doi.org/10.3201/eid1301.060487 PMID:17370535
26. Perevoscikovs J, Lucenko I, Magone S, Brila A, Curikova J, Vennema H. Community-wide outbreak of hepatitis $A$ in Latvia in 2008 - an update. Euro Surveill. 2009;14(3):19092. PMID:19161728

27. Edelstein M, Turbitt D, Balogun K, Figueroa J, Nixon G. Hepatitis A outbreak in an Orthodox Jewish community in London, July 2010. Euro Surveill. 2010;15(37):19662. PMID:20929646

28. Gallot C, Grout L, Roque-Afonso AM, Couturier E, CarrilloSantisteve P, Pouey J, et al. Hepatitis A associated with semidried tomatoes, France, 2010. Emerg Infect Dis. 2011;17(3):566-7. http://dx.doi.org/10.3201/eid1703.101479 PMID:21392466

29. Nordic Outbreak Investigation Team C. Joint analysis by the Nordic countries of a hepatitis A outbreak, October 2012 to June 2013: frozen strawberries suspected. Euro Surveill. 2013;18(27):20520. http://dx.doi.org/10.2807/1560-7917. ES2013.18.27.20520 PMID:23870076

30. European Centre for Disease Prevention and Control (ECDC). European Food Safety Authority. Update: outbreak of hepatitis A virus infection in Italy and Ireland. Rapid outbreak assessment. Stockholm: ECDC; July 2013. Available from: http://ecdc.europa.eu/en/publications/Publications/ROAupdate_HAV_Italy_Ireland-final.pdf

31. Robesyn E, De Schrijver K, Wollants E, Top G, Verbeeck J, Van Ranst M. An outbreak of hepatitis $A$ associated with the consumption of raw beef. J Clin Virol. 2009;44(3):207-10. http://dx.doi.org/10.1016/j.jcv.2008.12.012 PMID:19179106

32. US Food and Drug Administration. (US FDA). Bad Bug Book: Foodborne Pathogenic Microorganisms and Natural Toxins Handbook, Hepatitis A Virus. Silver Spring: US FDA; 2014. Available from: http://www.fda.gov/Food/ FoodbornelllnessContaminants/CausesOfIllnessBadBugBook/ ucm071294.htm

33. US Food and Drug Administration. (US FDA), BAM 26B: Detection of Hepatitis A Virus in Foods. Silver Spring: US FDA; 2015. Available from: http://www.fda.gov/Food/ FoodScienceResearch/LaboratoryMethods/ucm374006.htm

34. Leder K, Torresi J, Libman MD, Cramer JP, Castelli F, Schlagenhauf P, et al.GeoSentinel Surveillance Network. GeoSentinel surveillance of illness in returned travelers, 2007-2011. Ann Intern Med. 2013;158(6):456-68. http:// dx.doi.org/10.7326/0003-4819-158-6-201303190-00005 PMID:23552375

35. Gossner CM, de Jong B, Hoebe CJPA, Coulombier D, and European Food and Waterborne Diseases Study Group. Event-based surveillance of food-and waterborne diseases in Europe: A six-year review of urgent inquiries, 2008-2013. Euro Surveill. 2015. Forthcoming. 